\title{
Transmission power transformer assessment using furan measurement with the aid of thermal model
}

DOI:

10.1109/CMD.2012.6416194

Link to publication record in Manchester Research Explorer

\section{Citation for published version (APA):}

Feng, D., Wang, Z., \& Jarman, P. (2012). Transmission power transformer assessment using furan measurement with the aid of thermal model. In Proceedings of 2012 IEEE International Conference on Condition Monitoring and Diagnosis, CMD 2012/Proc. IEEE Int. Conf. Cond. Monit. Diagn., CMD (pp. 521-524). IEEE.

https://doi.org/10.1109/CMD.2012.6416194

Published in:

Proceedings of 2012 IEEE International Conference on Condition Monitoring and Diagnosis, CMD 2012|Proc. IEEE Int. Conf. Cond. Monit. Diagn., CMD

\section{Citing this paper}

Please note that where the full-text provided on Manchester Research Explorer is the Author Accepted Manuscript or Proof version this may differ from the final Published version. If citing, it is advised that you check and use the publisher's definitive version.

\section{General rights}

Copyright and moral rights for the publications made accessible in the Research Explorer are retained by the authors and/or other copyright owners and it is a condition of accessing publications that users recognise and abide by the legal requirements associated with these rights.

\section{Takedown policy}

If you believe that this document breaches copyright please refer to the University of Manchester's Takedown Procedures [http://man.ac.uk/04Y6Bo] or contact uml.scholarlycommunications@manchester.ac.uk providing relevant details, so we can investigate your claim.

\section{OPEN ACCESS}




\section{Transmission Power Transformer Assessment Using Furan Measurement with the aid of Thermal Model}

\author{
Dongyin Feng and Zhongdong Wang ${ }^{*}$ \\ School of Electrical and Electronic Engineering \\ The University of Manchester, M13 9PL, UK \\ *E-mail: zhongdong.wang@manchester.ac.uk
}

\author{
Paul Jarman \\ National Grid \\ NG House, Warwick CV34 6DA, UK
}

\begin{abstract}
As a potential insulation condition assessment technique for the field transformer, the correlation of the furan, or more specifically 2-furfural (2-FAL) measurement in oil and the insulating paper's degree of polymerization (DP) has been studied intensively in the laboratory by the means of accelerated ageing experiments. However due to the complicated operating conditions and design characteristics the field transformers are subjected to, it is not sensible to directly apply the correlation of 2FAL and DP derived based on laboratory works. In this paper, the field 2-FAL measurements have been analyzed on 49 UK National Grid (NG) field transmission power transformers. The insulating paper's DP of these transformers are estimated with the aid of the transformer thermal model, which was developed based on the thermal model in IEC transformer loading guide. As a result, a practical correlation has been established between the field 2-FAL measurement and insulating paper's DP estimates. The fitted model indicates that there is a possibility of developing a practical furan-DP relationship as a reliable insulation condition assessment technique for the field transformer.
\end{abstract}

Index Terms-transmission power transformer; furan diagnosis; degree of polymerization; thermal modeling

\section{INTRODUCTION}

Although the transmission power transformer in the power system network is considered reliable, the deterioration of its material naturally occurs under any operating circumstance, and therefore the technical end-of-life of a transformer is inevitable [1].

A number of approaches have been developed to monitor the field transformer's oil-paper insulation condition in order to carry out proactive measures such as life prolonging maintenance, or total unit retirement. However since the transformer deterioration process is complex, no modern technique so far could possibly prevent every single failure incident [2].

Transformer's reliability is critically governed by the mechanical strength of the insulating paper wound on winding conductor. This can be represented by paper's degree of polymerization (DP) [3, 4]. Taking sample of the insulating paper is impractical on field transformers as it involves deenergization of the unit and the intrusive examination. As alternative approach, the concentration of furan dissolved in oil has become one of the most common parameters to have been measured. It has been verified by laboratory experiments that the concentration of furan dissolved in oil has strong correlation with paper's DP. This naturally makes the furan measurement an excellent candidate as a non-intrusive diagnostic technique for the field transformer. However directly applying the laboratory-derived correlation on field transformers would be doubtful due to the nature of far-morecomplicated structure of the real transformers and their dynamic operating conditions [5]. In this context there remains a great desire to develop a practical correlation of field transformer's furan measurements with the condition of the insulating paper.

In this paper, a brief literature review is firstly carried out to present the current knowledge in transformer furan analysis, more specifically the correlation of the furan concentration and transformer insulating paper's DP by means of accelerated ageing experiments. Considering the limitations of applying laboratory-derived correlations to the field transformers, the furan data of 49 National Grid UK (referred as NG in following context) field transmission power transformers are investigated. With the aid of transformer thermal modeling, the paper's DP is estimated and a practical correlation is established between the furan measurements and the paper's DP estimates. Fitting the furan-DP data, an equation is proposed to estimate the NG field transmission power transformer's paper DP using its furan measurements, aiming to create a reliable insulation condition assessment technique.

\section{REVIEW OF FURAN ANALYSIS IN LABORATORY}

Accelerated ageing experiments conducted in many laboratories have confirmed that during the paper degradation in transformer oil, the linkage of the glucose ring in cellulose is broken by hydrolytic decomposition and produces a variety of furanic compounds as intermediate ageing by-products. Five main furanic compounds have been identified which are 2furfural (2-FAL), furfuryl alcohol (2-FOL), 5-hydroxymethyl2-furaldehyde (5-HMF), 5-methyl-2-furaldehyde (5-MEF) and 2-acetylfuran (2-ACF). Among all members of, 2-FAL has been confirmed as having the highest generation rate and greatest stability dissolved in oil. This makes the concentration of 2-FAL the most popular one to be determined in furan measurement on field transformers $[5,6]$.

The increase of 2-FAL concentration in oil has been found in accordance with the reduction of paper's DP. By means of sealed ageing experiments under elevated temperature, a 
variety of researchers e.g. Chendong, Burton and Vuarchex have respectively established a correlation between the logarithm of 2-FAL concentration in oil and the paper's DP [5]. The derived correlations are shown as follows:

$$
\begin{aligned}
\mathrm{DP}_{\text {chendong }} & =\frac{1.51-\log _{10}(2-\mathrm{FAL})}{0.0035} \\
\mathrm{DP}_{\text {Burton }} & =\frac{2.5-\log _{10}(2-\mathrm{FAL})}{0.005} \\
\mathrm{DP}_{\text {Vuarchex }} & =\frac{2.6-\log _{10}(2-\mathrm{FAL})}{0.0049}
\end{aligned}
$$

where 2-FAL is the concentration of 2-furfural in oil expressed in milligrams per liter ( $\mathrm{ppm})$.

As an alternative form, De Pablo has developed (4) to relate 2-FAL in oil with paper's DP, based on the theory of cellulose chain scissions [7]:

$$
\mathrm{DP}_{\text {De Pablo }}=\frac{7100}{(2-\mathrm{FAL})+8.88}
$$

where 2-FAL is also expressed in milligrams per liter (ppm). It is worth mentioning that the initial DP of the paper was assumed as 800 in De Pablo's study, which was lower than the expected value in real transformers which is approximately 1000 .

Plotting (1) to (4) together as shown in Fig. 1, the variation of the DP estimates yielded by these equations can be illustrated. The 2-FAL values corresponding to critical DP values are summarized in TABLE I below.

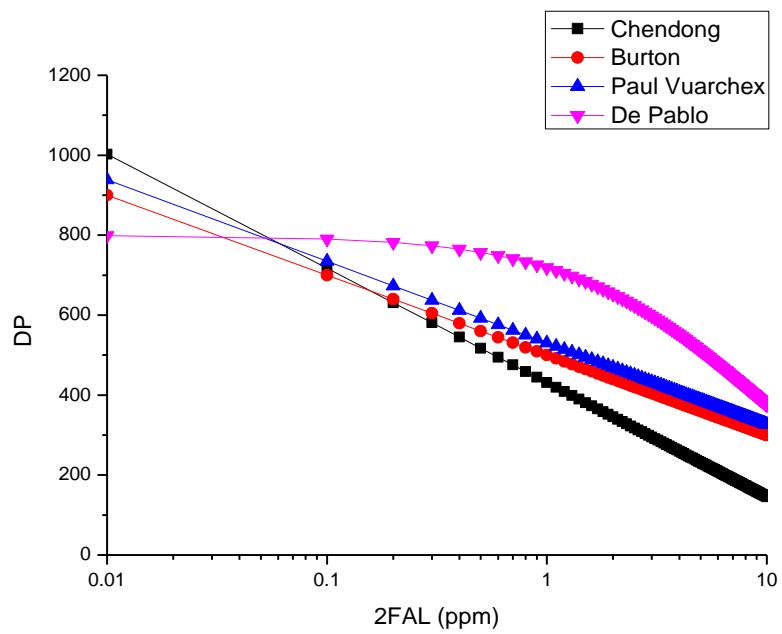

Figure 1. Comparison of the 2-FAL concentration in oil and paper's DP correlations derived in different laboratories

It can be seen that by using different equations, the 2-FAL concentration estimates are close at the early stage of the paper ageing, but the scattering tends to be greater at lower DP levels of the insulating paper because of the differently defined ageing conditions. Looking at DP of 200 in particular which has been widely recognized as paper's end-of-life, the corresponding 2-FAL values vary from $6.46 \mathrm{ppm}$ to $41.69 \mathrm{ppm}$.
In field transformers, this uncertainty would be even further exaggerated due to variety of factors such as different paper-oil ratio, thermal performance and partitioning of furans in paper and oil which depends on ambient temperature and dynamic loading. Therefore it is not advisable to directly apply any of the furan-DP correlation derived from accelerated ageing experiments on field transformers for the purpose of insulation condition assessment [5].

TABLE I. 2-FAL VALUES CORRESPONDING TO CRITICAL DP LEVELS

\begin{tabular}{|c|c|c|c|}
\hline $\begin{array}{c}\text { 2-FAL } \\
(\mathrm{ppm})\end{array}$ & $\begin{array}{c}\mathrm{DP}=800 \\
\text { (early stage) }\end{array}$ & $\begin{array}{c}\mathrm{DP}=400 \\
\text { (moderate) }\end{array}$ & $\begin{array}{c}\mathrm{DP}=200 \\
\text { (end of life) }\end{array}$ \\
\hline Chendong & $\mathbf{0 . 0 5}$ & 1.29 & 6.46 \\
\hline Burton & $\mathbf{0 . 0 3}$ & 3.16 & 31.62 \\
\hline Vuarchex & $\mathbf{0 . 0 5}$ & 4.37 & 41.69 \\
\hline De Pablo & 0.00 & 8.87 & 26.62 \\
\hline
\end{tabular}

\section{FURAN ANALYSIS OF NG FIELD TRANSFORMERS}

In this section, the furan data of $49 \mathrm{NG}$ field transmission power transformers are presented and analyzed. With the aid of transformer thermal modeling, the DP of these transformers' insulating papers can be estimated. By plotting the transformer population's furan measurements against the paper's DP estimates, a relationship can be determined through fitting the data using specific functions.

\section{A. 49 NG Field Transformers' Furan Data}

49 of NG field transmission power transformers have had their furan concentration in oil measured. All units have voltage levels of either $400 / 132$ or $275 / 132 \mathrm{kV}$. The ratings vary from 120 to $240 \mathrm{MVA}$. The service age of these 48 units ranges from 21 to 57 years.

In terms of the furan measurement, according to NG, there had been some changes of contractor in the past. Considering the coherence of the measurement, only the last batch of furan data measured by the same institution is analyzed which were obtained between 2006 and 2011. The oil of each unit was sampled with rather different frequency, varying from months to years. The main derivative among all furanic compounds measured is $2-\mathrm{FAL}$. Therefore only $2-\mathrm{FAL}$ is analyzed in this study, and all other furanic compounds are considered minor and disregarded.

It is worth mentioning that majority of the transformers owned by NG did not had their oil reclaimed in recent years due to company policy. Therefore in this study it is assumed that the oil of these 49 transformers has remained in the main tank, which eliminates the issue of the furan removal due to the oil change. The 2-FAL measurements of the 49 transformers in between 2006 and 2011, counted as 222 in total, are plotted in Fig. 2 below against the transformer's service age.

As shown in the figure, the 2-FAL measurement in the NG transformer oil does not increase monotonously with age. The 2-FAL level increases to a peak at age of 42 , and then drops

This project is sponsored by National Grid UK. 
afterwards. The scatter in the plot appears to be normally distributed.

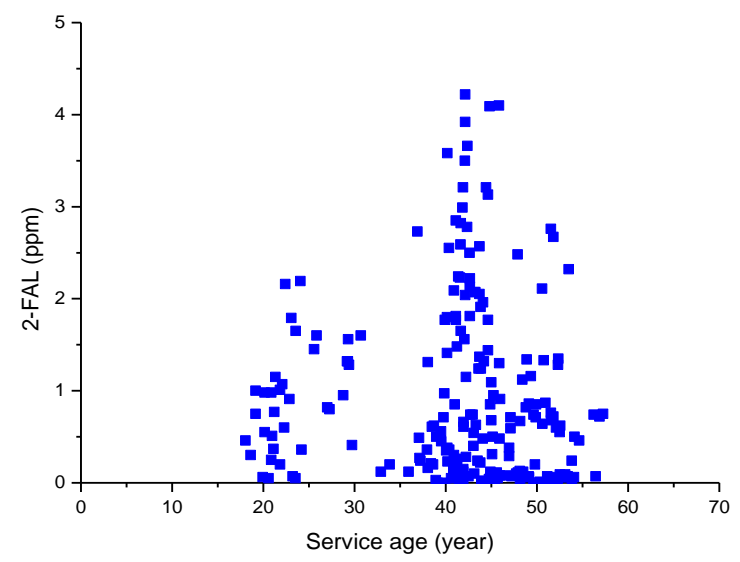

Figure 2. 49 NG field transformers' 2-FAL plot against service year

\section{B. Paper's DP Estimation Using Thermal Modeling}

Since there is yet no reliable technique to assess the DP of active transformer's insulating paper non-intrusively, in this study an alternative approach, transformer thermal modeling, is adopted to estimate the DP of NG field transformer's insulating paper. The model is developed based on the thermal model in IEC transformer loading guide [8], and the detailed development is presented in [9]. A simplified modeling procedure is illustrated in Fig. 3 below.

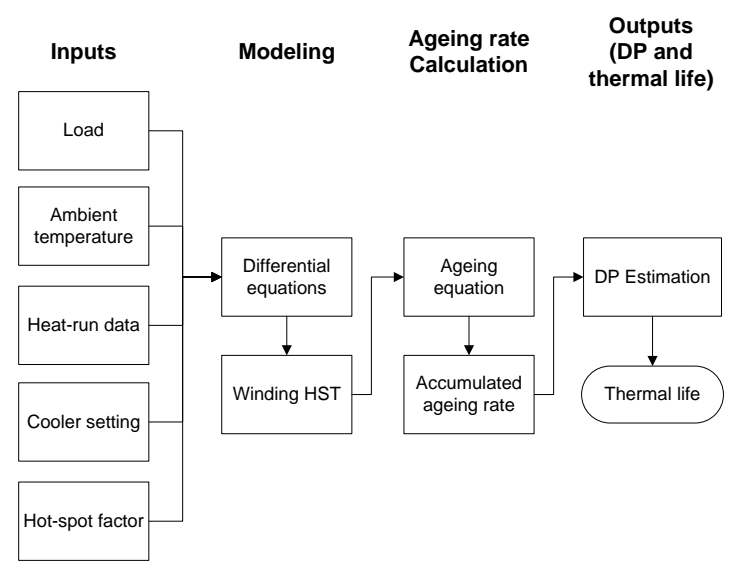

Figure 3. Simplified thermal model procedure

As a brief explanation of the modeling procedure, the transformer's operating conditions and thermal design characteristics are input into the differential equations to estimate the winding hot-spot temperature (HST). Inserting the HST into the ageing equation i.e. Arrhenius equation, the ageing rate $k$ can be calculated depending on the paper's ageing mechanism (i.e. oxidation and hydrolysis). The paper's DP can thereby be estimated by (5), where $D P_{0}$ and $D P_{t}$ represent the initial and retained DP, after degradation time $t$. The thermal life of the transformer can be estimated by assigning $D P_{0}$ and $D P_{t}$ as 1000 and 200 respectively. Furthermore, the paper's DP at any transformer age can be estimated using the same equation (5) by substituting $t$ with the service age. By this means the possible correlation between the DP estimates and 2FAL measurement in oil at certain transformer age can therefore be investigated.

$$
\frac{1}{D P_{t}}-\frac{1}{D P_{0}}=k t
$$

\section{NG Field Transformers' Furan-DP Correlation Analysis}

As an overview of the relationship between the NG field transformers' 2-FAL measurements and their insulating paper DP estimates, the 2-FAL and DP estimates are plotted against the ratio of modeling life and service year as shown in Fig. 4.

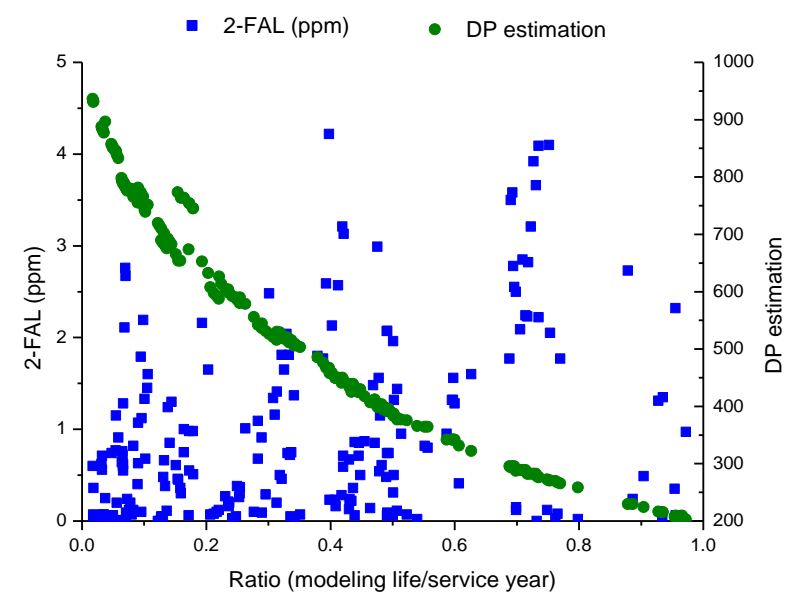

Figure 4. Plot of 49 NG transformers' 2-FAL and DP estimates against the ratio of modeling life and service year

Since the modeled life represents the number of years it takes the transformer to reach the insulating paper's end-of-life, this life is regarded as the transformer's ultimate life. By plotting the paper's DP estimates against the ratio of modeled life and service year, one could well observe the decreasing trend in paper's DP as the transformer's end-of-life is approached. The trend of 2-FAL against life ratio is rather difficult to determine. This is most probably caused by the partitioning of 2-FAL in between paper and oil at different temperatures. However a general increasing trend can be characterized in Fig. 4 as the transformer approaches the endof-life.

To derive the correlation between field transformers' 2FAL measurement and paper's DP estimates, they are firstly plotted against each other, shown as the blue marks in Fig. 5. Since 2-FAL scatters greatly, to better reveal the increase of 2FAL in oil in accordance with paper's DP reduction, the data in each 2-FAL bin has been averaged as shown in red marks connected with lines.

The functions of logarithmic form, as in (1) to (3), and De Pablo's chain scission theory (4) are used to fit the data of the scattered 2-FAL against paper's DP estimates. The plots of the fitted functions are shown as the green and red lines in Fig. 5. The fitted functions are shown as (6) and (7). 


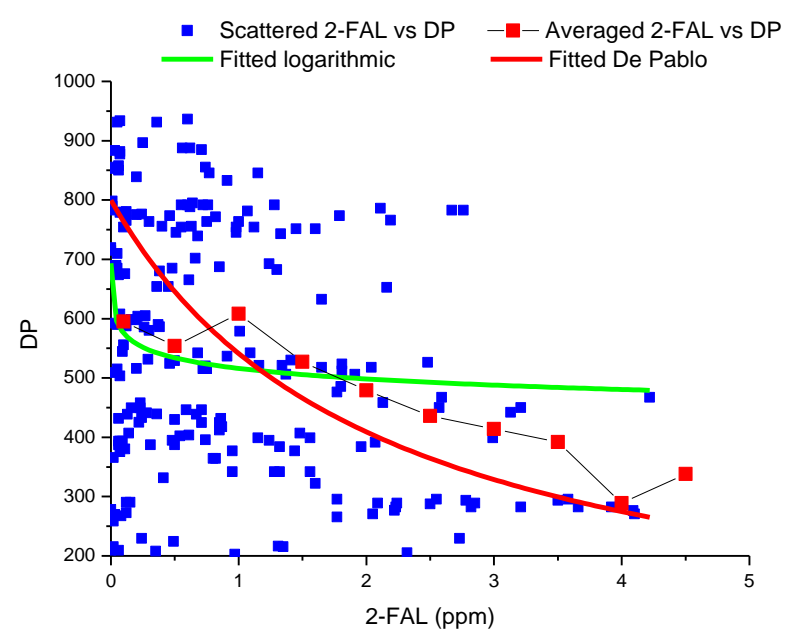

Figure 5. Plot of 49 NG transformers' 2-FAL against DP estimates and the fitted functions

$$
\begin{gathered}
\mathrm{DP}_{\text {Fitted De Pablo }}=\frac{1674}{(2-\mathrm{FAL})+2.09} \\
\mathrm{DP}_{\text {Fitted logarithmic }}=\frac{20.12-\log _{10}(2-\mathrm{FAL})}{0.04}
\end{gathered}
$$

As shown in Fig. 5, the logarithmic function features a rapid drop of DP at low levels of detected 2-FAL (DP drops to 541 at 2-FAL of $0.1 \mathrm{ppm})$. The rate of DP reduction tends to be extremely insensitive to the increase of 2-FAL beyond $0.1 \mathrm{ppm}$, and eventually levels off. Neither of these properties is coherent with practical experience.

De Pablo's function on another hand yields a better goodness of fit than the logarithmic function in general, despite the inaccurate fitting at low 2-FAL levels (less than 1ppm) which are considered to be trivial in field transformer furan diagnostics. Furthermore, according to the fitted function (6), the corresponding 2-FAL value when DP drops to 200 is 6.28 ppm, which is coherent with the fact that the 2-FAL measurement on $49 \mathrm{NG}$ field transformers has never exceeded $5 \mathrm{ppm}$. This indicates that the fitted function (6), which follows De Pablo's theory of cellulose chain scission, is superior in fitting the NG field furan data. It is therefore proposed in this paper to introduce (6) as a potential candidate in assessing the NG field transformer's furan measurement. TABLE II below can be used as a furan-DP guideline.

TABLE II. 2-FAL VALUES CORRESPONDING TO CRITICAL DP LEVELS PREDICTED USING (6)

\begin{tabular}{|c|c|c|c|}
\hline $\begin{array}{c}\text { 2-FAL } \\
\text { (ppm) }\end{array}$ & $\begin{array}{c}\text { DP=800 } \\
\text { (early stage) }\end{array}$ & $\begin{array}{c}\mathrm{DP}=\mathbf{4 0 0} \\
(\text { moderate) }\end{array}$ & $\begin{array}{c}\mathrm{DP}=\mathbf{2 0 0} \\
\text { (end of life) }\end{array}$ \\
\hline $\begin{array}{c}\text { Proposed } \\
\text { equation (6) }\end{array}$ & $<0.01$ & 2.09 & 6.28 \\
\hline
\end{tabular}

\section{CONCLUSIONS}

As a potential insulation condition assessment technique for the field transmission power transformer, the correlation between insulating paper's DP and the furans produced and dissolved in oil has been studied intensively in laboratories by the means of accelerated ageing experiments. However due to the complicated operating conditions and different design characteristics field transformers are subjected to, it is not sensible to directly apply any of these lab-derived correlations.

This paper has proposed to correlate the field transformer's furan measurement with DP estimates of the insulating paper, with the aid of transformer thermal modeling. The 2-FAL measurements from $49 \mathrm{NG}$ field transformers have been collected and analyzed. After plotting the 2-FAL measurements with the DP estimates of transformer's insulating paper, both logarithmic and De Pablo's chain scission theory are used to fit the data. It is found that the De Pablo function better describes NG transformer's DP reduction along with the increase in 2FAL measurement.

The fitted equation indicates a tangible progress towards a practical furan-DP equation based on field data in terms of a reliable insulation condition assessment technique.

\section{ACKNOWLEDGMENT}

The authors would like to express their sincere gratitude to the UK National Grid Company for the technical and financial supports to the research on "Transformer end-of-life modeling" at the University of Manchester. Dongyin Feng would like to express his gratitude to the UK National Grid Company for partially funding his $\mathrm{PhD}$ research study.

\section{REFERENCES}

[1] Q. Zhong, Z.D. Wang, and P. Crossley, "Power transformer end-of-life modelling: linking statistical approach with physical ageing process," in CIRED Workshop, Lyon, France, 2010.

[2] D. Feng, Z.D. Wang, and P. Jarman, "Getting the most out of historic reliability data," in Prognostics and System Health Management Conference, Beijing, China, 2012.

[3] M. Heathcote, A. Franklin, and D. Franklin, The J \& P transformer book: Newnes, 1998.

[4] P. Jarman, R. Hooton, L. Walker, Q. Zhong, T. M. Ishak, and Z.D. Wang, "Transformer life prediction using data from units removed from service and thermal modelling," in CIGRE Session 2010, Paris, France, 2010.

[5] L. Cheim, D. Platts, T. Prevost, and S. Xu, "Furan analysis for liquid power transformers," Electrical Insulation Magazine, IEEE, vol. 28, pp. 8-21, 2012.

[6] T. V. Oommen and T. A. Prevost, "Cellulose insulation in oil-filled power transformers: part II maintaining insulation integrity and life," IEEE Electrical Insulation Magazine, vol. 22, pp. 5-14, 2006.

[7] A. de Pablo, "Furfural and ageing: how are they related," in Insulating Liquids (Ref. No. 1999/119), IEE Colloquium on Leatherhead , UK, 1999 , pp. $5 / 1-5 / 4$.

[8] "IEC 60076-7 Power Transformers-Part7: Loading Guide for OilImmersed Power Transformers," IEC Standard, 2005.

[9] D. Y. Feng, W. Wu, Z.D. Wang, and P. Jarman, "Transmission transformer end-of-life modelling: incorporating insulating paper's thermal lifetime analysis with ordinary statistical analysis," in 17th International Symposium on High Voltage Engineering, Hannover, Germany, 2011. 